CASE REPORT

T.J. Hodgson

A.A. Kemeny

A. Gholkar

N. Deasy

\section{Embolization of Residual Fistula Following Stereotactic Radiosurgery in Cerebral Arteriovenous Malformations}

\begin{abstract}
SUMMARY: Treatment of brain arteriovenous malformations (BAVMs) often requires a multitechnique approach. We present 2 cases of BAVM, in which initial stereotactic radiosurgery (SRS) was successful in obliterating a significant volume of the nidus. At follow-up angiography, residual fistulas were identified and selectively embolized; this procedure cured the lesions. Many series describe initial embolization to reduce the nidal volume followed by SRS to the remnant. The described cases highlight the value of primary radiosurgery followed by selective fistula embolization.
\end{abstract}

B rain arteriovenous malformations (BAVMs) may be treated with open microsurgery, embolization, stereotactic radiosurgery (SRS), or a combination of all 3 techniques. There are several series in the literature describing initial embolization followed by focused SRS to the residual nidus. The 2 cases described highlight the value of primary radiosurgery followed by selective embolization of residual fistulas.

\section{Case Reports}

A 19-year-old man presented with focal seizures involving the right arm. Subsequent investigations revealed a large BAVM within the right superior frontal gyrus with extension into the internal capsule, basal ganglia, and precentral gyrus (Fig 1A). Primary embolization was considered, but given the eloquence of the area and potential morbidity, SRS was considered the treatment of choice. Gamma knife SRS was performed; 20 Gy was administered to the $50 \%$ isodose. Follow-up angiography after 4 years revealed significant nidal obliteration but with 2 persistent fistulas supplied via a hypertrophied right pericallosal artery (Fig $1 B$ ). A further session of SRS was considered, but given the usual poor response of direct fistulas to SRS, targeted embolization was performed by using Onyx 34 (ev3, Irvine, Calif). Both fistulas were obliterated without complication. Sixmonth postembolization angiography revealed that the BAVM was cured (Fig 1C).

A 62-year-old woman presented with focal seizures, and subsequent investigations revealed a large left frontoparietal BAVM (Fig $2 A)$. Embolization to reduce the nidus was considered, but the operator did not think a segmental nidal reduction could be performed. After we discussed the options with the patient, she elected primary SRS. At the treatment session, 20 Gy was administered to the $50 \%$ isodose. Follow-up angiography at 4 years revealed a significant reduction in the size of the nidus, but a residual fistula persisted, feeding from a hypertrophied pericallosal artery (Fig 2B). Targeted embolization was performed by using $70 \% n$-butyl 2 -cyanoacrylate, resulting in closure of the fistula (Fig 2C). Follow-up angiography confirmed persistent occlusion.

Received April 17, 2008; accepted after revision June 10

From the National Department of Stereotactic Radiosurgery/Department of Radiology (T.J.H., A.A.K.), Royal Hallamshire Hospital, Sheffield, UK; Department of Neuroradiology (A.G.), Newcastle General Hospital, Newcastle-upon-Tyne, UK; and Department of Neuroradiology (N.D.), King's College Hospital, London, UK.

Please address correspondence to Timothy J. Hodgson, MD, National Department of Stereotactic Radiosurgery/Department of Radiology, Royal Hallamshire Hospital, Glossop Rd, Sheffield S10 2JF, UK; e-mail: tim.hodgson@sth.nhs.uk

DOI 10.3174/ajnr.A1240

\section{Discussion}

BAVMs, which are probably genetically determined lesions, may present with a variety of symptoms-hemorrhage, seizures, or headaches. With brain imaging increasingly performed, asymptomatic BAVMs are being identified more frequently. The risk of hemorrhage from unruptured BAVMs has recently been reviewed, with Stapf et $\mathrm{al}^{1}$ reporting an annual rupture rate of $1.3 \%$, lower than the previously accepted figure of approximately $2 \%$. Treatment options, therefore, have to be considered carefully. Open microsurgery, endovascular embolization, SRS, or a combination of these techniques should be discussed with the patient.

SRS is a recommended treatment for BAVMs $<3 \mathrm{~cm}$ when microsurgery is precluded. For BAVMs $>3 \mathrm{~cm}$, treatment recommendations include embolization to reduce nidal volume followed by SRS to the remnant. ${ }^{2}$ However, the potential morbidity of embolization and SRS may be significant, with several series describing complications of both techniques.

Reported complication rates of BAVM embolization range from $9.1 \%{ }^{3}$ to $22 \% .{ }^{4}$ Recent reports are now emerging, describing experience with a liquid polymer agent, Onyx. Mounayer et $\mathrm{al}^{5}$ reported a lower complication rate of $8.5 \%$ with Onyx, with 3 procedure-related deaths.

Complication and obliteration rates after SRS have been reported in several series. Pollock et $\mathrm{al}^{6}$ reviewed 144 patients who had undergone primary radiosurgery. Follow-up was between 5 and 14 years. The group achieved a 73\% cure rate, but $14 \%$ of the group developed a major deficit post-SRS, including patients who rehemorrhaged.

In addition to the combined complications of both techniques, there are reports analyzing obliteration rates when SRS has been preceded by embolization. Pollock et al, ${ }^{7}$ in a study of 220 patients undergoing SRS, found previous embolization a negative predictor of obliteration. Schlienger et $\mathrm{al}^{8}$ studied 169 patients treated with linear accelerator radiosurgery, of whom $36 \%$ had undergone previous embolization. The obliteration rate was $54 \%$ in those in the previous-embolization group compared with $71 \%$ in a matched group who had been treated primarily with SRS and no embolization $(P=.03)$.

SRS is most effective in treating a BAVM nidus but is least effective in direct arteriovenous fistulas. ${ }^{9}$ Identifying direct fistulas on conventional angiography may be difficult and, in most cases, will require a microcatheter exploration with or without embolization. The described cases illustrate the value of primary SRS obliterating the nidus to reveal residual fistulas, which may then be selectively embolized. As a technique, it 

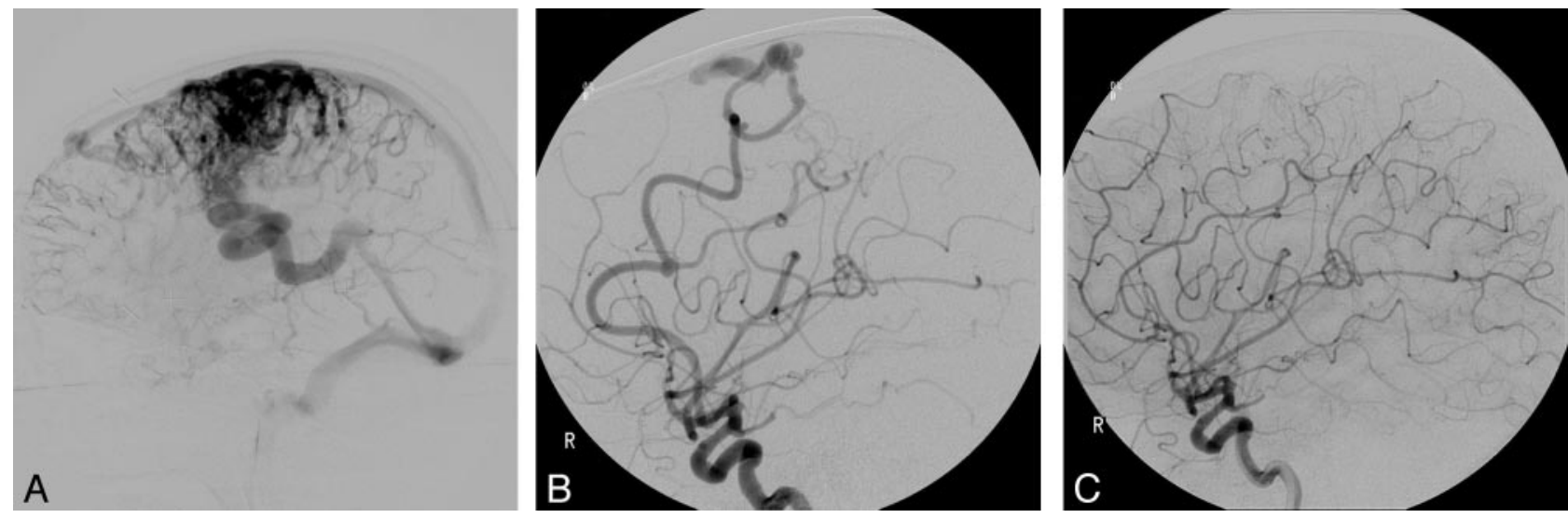

Fig 1. $A$, Initial angiogram reveals a large diffuse arteriovenous malformation (AVM) nidus. B, Follow-up angiogram at 4 years post-SRS reveals significant nidal obliteration with persistence of 2 fistulas. C, Angiogram 6 months after embolization shows complete AVM and fistula cure.
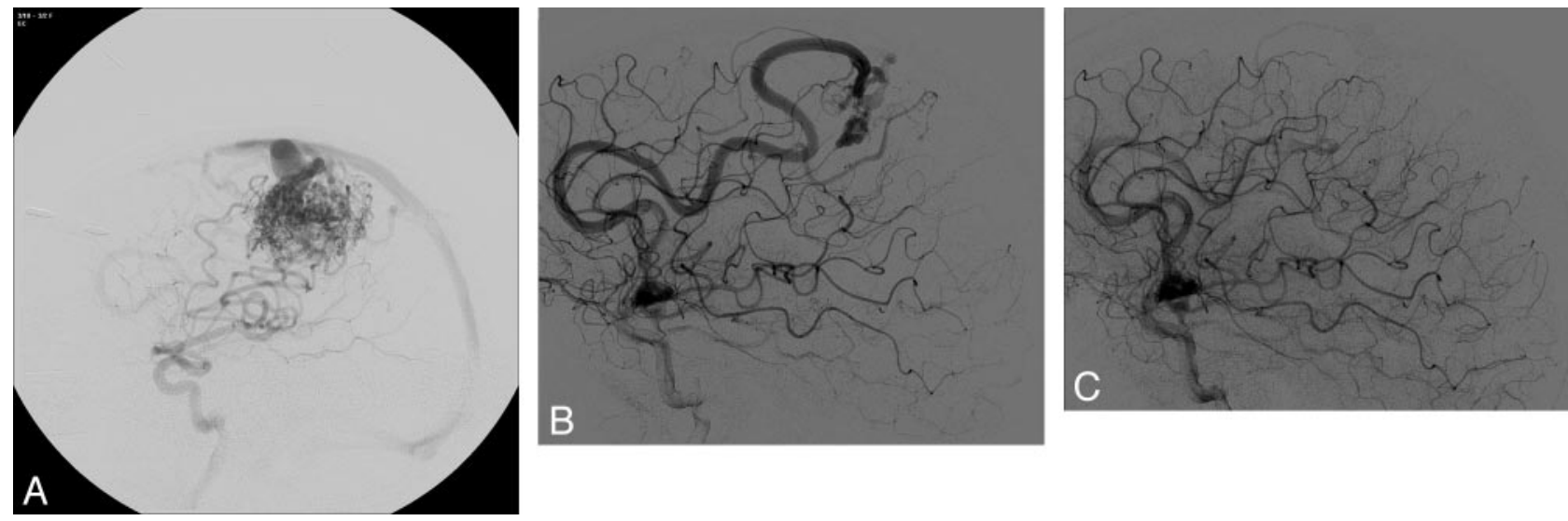

Fig 2. A, Initial angiogram reveals a large frontoparietal BAVM. B, Follow-up angiogram at 4 years post-SRS reveals significant nidal obliteration with a persistent fistula supplied via a hypertrophied pericallosal artery. C, Angiogram immediately postembolization reveals fistula closure.

is not widely reported. Luo et $\mathrm{al}^{10}$ described residual fistula embolization by using detachable coils following partial nidal obliteration after SRS in a 37-year-old patient.

We believe the described cases offer a further option in BAVM treatment. SRS planning of the BAVM nidus is usually easier and may be more effective without pre-embolization. In both cases, the SRS obliterated the BAVM nidus, allowing the direct arteriovenous fistulas to be clearly identified. The fistulas could then be treated with superselective catheterization and targeted embolization.

\section{References}

1. Stapf C, Mast H, Sciacca RR, et al. Predictors of hemorrhage in patients with untreated brain arteriovenous malformations. Neurology 2006;66:1350-55

2. Ogilvy CS, Stieg PE, Awad I, et al, for the Special Writing Group of the Stroke Council, American Stroke Association. AHA scientific statement: recommendations for the management of intracranial arteriovenous malformations-a statement for healthcare professionals from a special writing group of the Stroke Council, American Stroke Association. Stroke 2001;32:1458-71
3. Beltramello A, Zanpieri P, Ricciardi GK, et al. Combined treatment of brain AVMs: analysis of five years (2000-2004) in the Verona experience. Interv Neuroradiol 2005;11(suppl 1):63-72

4. Raymond J, Iancu D, Weill A, et al. Embolization as one modality in a combined strategy for the management of cerebral arteriovenous malformations. Interv Neuroradiol 2005;11(suppl 1):57-62

5. Mounayer C, Hammami N, Piotin M. Nidal embolization of arteriovenous malformations using Onyx in 94 patients. AJNR Am J Neuroadiol 2007;28:518-23

6. Pollock BE, Gorman DA, Coffey RJ. Patient outcomes after arteriovenous malformation radiosurgical management: results based on a 5- to 14-year follow-up study. Neurosurgery 2003;52:1291-97

7. Pollock B, Flickinger JC, Lunsford LD, et al. Factors associated with successful arteriovenous malformation radiosurgery. Neurosurgery 1998;42:1239-47

8. Schlienger M, Atlan D, Lefkopoulos D, et al. Linac radiosurgery for cerebral arteriovenous malformations in $\mathbf{1 6 9}$ patients. Int J Radiat Oncol Biol Phys 2000;46:1135-42

9. Kwon Y, Jeon SR, Kim JH, et al. Analysis of the causes of treatment failure in gamma knife radiosurgery for intracranial arteriovenous malformations. J Neurosurg 2000;93(suppl 3):4-6

10. Luo CB, Guo WY, Teng MM, et al. Embolization of arteriovenous fistula after radiosurgery for multiple cerebral arteriovenous malformations. Kaohsiung J Med Sci 2005;21:571-77 